\title{
Changes in Prenatal Depression and Anxiety Levels in Low Risk Pregnancy Among Iranian Women: A Prospective Study
}

\author{
Ashraf Kazemi ( $\square$ kazemi@nm.mui.ac.ir) \\ Isfahan University of Medical Sciences https://orcid.org/0000-0001-7182-0012 \\ Aazam Dadkhah \\ Isfahan University of Medical Sciences
}

\section{Research article}

Keywords: Depression, Anxiety, Low Risk Pregnancy, Iran

Posted Date: April 17th, 2020

DOI: https://doi.org/10.21203/rs.3.rs-21295/v1

License: (a) (i) This work is licensed under a Creative Commons Attribution 4.0 International License. Read Full License

Version of Record: A version of this preprint was published at Asia-Pacific Psychiatry on September 2nd, 2020. See the published version at https://doi.org/10.1111/appy.12419. 


\section{Abstract}

Background There is limited information on the changes in uncomplicated pregnancies. Therefore, in the present study, the changes of depression and anxiety changes in uncomplicated pregnancies during the prenatal period was evaluated.

Method This longitudinal study was performed on 256 pregnant women at the beginning of the first trimester of pregnancy. Inclusion criteria included the absence of pre-pregnancy depression and anxiety and poor pregnancy history. Exclusion criteria were the incidence of pregnancy complications. The level of their depression and anxiety at the time of entering the study were completed by self-report using the DASS questionnaire at 9-10, $11-12,24-25$, and $33-35$ weeks of pregnancy.

Results The results of the study indicated the effect of time on the level of perinatal depression and anxiety $(p<$ 0.001). These findings showed that the level of depression increased significantly from 9 to 24 weeks of pregnancy and decreased in the 32-34 weeks, but did not reach the level of depression at 9 weeks of pregnancy. Also, the anxiety level increased significantly from the onset of pregnancy to the 24 weeks gestation but did not change during the second and third trimesters. The findings of the study showed that depression and anxiety levels in each of the pregnancy termites were related to its level in the previous trimesters.

Conclusion The results of the study showed that the level of depression and anxiety of women in uncomplicated pregnancies also increases. Therefore, psychological health screenings in the second trimester of pregnancy should be performed in these women.

\section{Background}

Depression and anxiety are one of the most prevalent experiences of pregnancy and can be associated with some maternal and fetal pregnancy complications. The probability of preeclampsia [1] and eventually weak infant [2-4] and insufficient growth during fetal development [5] are increased due to psychological disorders during pregnancy. A recent report has been presented on the relationship between changes in the brain structure of children and pregnancy anxiety, which can be associated with behavioral problems [6]. In this period, the probability of suicide [7] and disorder in the development of maternal roles also increases. Bonding [8] and postpartum depression [9] are complications reported due to psychological disorders during pregnancy. Pregnancy is a unique period of time with dramatic changes in women's physical and biological conditions. Although these physiological changes are necessary to adapt the body to pregnancy and parturition, it creates special conditions for pregnant women. Morning nausea, headache, increased volume of the abdomen, back pain, Lordosis, movement constraints, and lack of sleep are the most common disorders of pregnancy. In addition, constraints on sexual intercourse due to physical conditions [10] and the possibility of injury to the fetus in particular cases [11], the probability of complications of pregnancy and the limitation of some of the usual behaviors that are inconsistent with the health of the fetus can be factors that affect women's psychological status $[12,13]$. Increasing the need for a partner's attention, feeling more vulnerable, and more needing a partner's emotional support are also ecological factors that may make women vulnerable to psychological disorders. 
Several predisposing factors for these disorders are known. High-risk pregnancy [14], history of pre-pregnancy psychological disorders [15], stressful events during pregnancy [16], and economic and social factors [17, 18], are known risk factors. The importance of identifying women at risk of depression and anxiety during pregnancy has led screening programs to be included in many prenatal care programs in developed countries [19]. But widespread and comprehensive changes during pregnancy may have a different effect on the psychological health of women during different stages of the prenatal period and it needs to be aware of changes in psychological health during different periods of pregnancy. However, in previous studies, the psychological conditions of pregnant women evaluated during pregnancy; but, there is limited information on the changes in psychological status during low-risk pregnancies [20]. Therefore, the present study was conducted by designing prospective study with the aim of evaluating the changes in psychological symptoms of women with uncomplicated pregnancy.

\section{Methods}

This is a longitudinal prospective study that was approved by the Ethics Committee of the Isfahan University of Medical Sciences between April 2017 and January 2018. A total of 310 pregnant women with a spontaneous singleton pregnancy were enrolled in the first trimester of pregnancy in Isfahan-Iran health centers. The inclusion criteria included age from 18 to 35 years old, no history of congenital disorders, recurrent abortion, and infertility, history of complications in previous pregnancies, and absence of systemic diseases in pregnancy, as well as no known psychological disorders before pregnancy. Exclusion criteria were the occurrence of stressful events during pregnancy and the incidence of pregnancy complications. Selection of health centers was performed as stratified random sampling. Selection of research samples was done as simple random sampling. So that, the subjects were randomly selected from pregnant women with gestational age of 9-10 weeks, and the inclusion criteria were evaluated by interviewing and evaluating the pregnancy care case. After obtaining informed written consent from the qualified individuals, demographic characteristics were recorded and the level of depression and anxiety was measured by two subscales of the standard DASS-21-Farsi questionnaire as self-report [21] at 11-12, 24-25 and 33-35 weeks of gestational age. This Likert scale has four options: did not apply to me at all (0)\ $\$ applied to me to some degree, or some of the time (1); applied to me to a considerable degree or a good part of time (2); and applied to me very much or most of the time (3).

It was set up to assess the conditions of individuals over the past week. The incidence of pregnancy complications and stressful events during the study was followed up and recorded, and information related to the psychological symptoms after their occurrence was not included in the data analysis. The criteria for determining the presence of anxiety disorder (mild, moderate, and severe anxiety): anxiety score was higher than 7 and depression disorder was higher than 9. Data analysis was conducted using SPSS version 19, and such statistical methods as multivariable linear regression analysis, RMANOVA, and Cochran's Q.

\section{Results}

Of the 310 people invited, 256 accepted to participate in the study. The characteristics of the study units and the level of their psychological indicators are presented in Table 1 in the four time periods. These results indicate that women were mostly "housewives with secondary education and diplomas and their pregnancy was wanted 
and planned. Also, the relative frequency of those who had some degree of anxiety and depression was lower at the beginning of the study than in other times.

Table 1

Profiles and the levels of psychological markers of participants

\begin{tabular}{|c|c|}
\hline Mean (SD) or Number (\%) & \\
\hline Age & $29.39(4.6)$ \\
\hline \multicolumn{2}{|l|}{ Educational level } \\
\hline Less than high school (\%) & $26(10.2)$ \\
\hline High school \& diploma (\%) & $107(41.8)$ \\
\hline University degree (\%) & $123(46.0)$ \\
\hline \multicolumn{2}{|l|}{ Occupation status (\%) } \\
\hline Employed & $26(9.5)$ \\
\hline \multicolumn{2}{|l|}{ Pregnancy planning (\%) } \\
\hline Wanted /Planed & $157(61.3)$ \\
\hline Wanted /Unplanned & $74(28.9)$ \\
\hline Unwanted /Unplanned & $25(9.8)$ \\
\hline \multicolumn{2}{|l|}{ Anxiety levels } \\
\hline Time 1 & $3.1(3.8)$ \\
\hline Time 2 & $7.6(6.3)$ \\
\hline Time 3 & $8.1(8.0)$ \\
\hline Time 4 & $6.3(6.0)$ \\
\hline \multicolumn{2}{|l|}{ Depression levels } \\
\hline Time 1 & $2.8(4.3)$ \\
\hline Time 2 & $7.3(7.1)$ \\
\hline Time 3 & $7.5(6.7)$ \\
\hline Time 4 & $5.9(4.5)$ \\
\hline Abbreviations: SD: standar & deviation \\
\hline
\end{tabular}

The use of the Kolmogorov-Smirnov test showed that the data related to the stress, anxiety, and depression levels have no normal distribution. Therefore, for data analysis, their tenth logarithm was used.

The level of depression at the beginning of the first trimester of pregnancy was negatively related to the level of education of women. The results indicated that the level of anxiety at the beginning of the first trimester of 
pregnancy had a reverse and significant relationship with the level of education and planned a pregnancy. At the end of the first, second, and third trimester of pregnancy, the level of anxiety and depression had a positive and significant relationship with the level of anxiety in the third trimesters of pregnancy (Table $2 \& 3$ ). The level of depression in the first trimester was lower than the second and third trimesters of pregnancy. There was no difference from the end of the first trimester to the second trimester. Between the second and third trimesters, depression decreased significantly (Table 4). Comparing the level of anxiety in different stages of the evaluation showed that the level of anxiety in the first trimester was significantly lower than the second and third trimesters. The level of anxiety had no differed from the end of the first trimester (T2) to the second trimester and was significantly higher than the third trimester.

Table 2

The relationship between the level of depression in four evaluation times and other variables studied

\begin{tabular}{|c|c|c|c|c|c|c|c|c|c|c|c|c|}
\hline \multirow[b]{4}{*}{ Age } & \multicolumn{12}{|c|}{ Depression levels } \\
\hline & \multicolumn{3}{|c|}{ Depression T 1} & \multicolumn{3}{|c|}{ Depression T2 } & \multicolumn{3}{|c|}{ Depression T3 } & \multicolumn{3}{|c|}{ Depression T4 } \\
\hline & \multirow{2}{*}{$\begin{array}{l}\text { Beta } \\
.07\end{array}$} & \multicolumn{2}{|c|}{ Cl 95\% } & \multirow{2}{*}{$\begin{array}{l}\text { Beta } \\
.04\end{array}$} & \multicolumn{2}{|c|}{ Cl 95\% } & \multirow{2}{*}{$\begin{array}{l}\text { Beta } \\
.01\end{array}$} & \multicolumn{2}{|c|}{ Cl 95\% } & \multirow{2}{*}{$\begin{array}{l}\text { Beta } \\
.07\end{array}$} & \multicolumn{2}{|c|}{ Cl 95\% } \\
\hline & & .02 & -.01 & & .02 & -.012 & & .01 & -.01 & & .02 & -.01 \\
\hline $\begin{array}{l}\text { Educational } \\
\text { levels }\end{array}$ & $-.20^{\star}$ & -.01 & -.29 & .13 & .23 & -.05 & -.08 & .06 & -.18 & -.01 & .09 & -.10 \\
\hline $\begin{array}{l}\text { Wanted } \\
\text { pregnancy }\end{array}$ & -.13 & .05 & -.37 & .07 & .29 & -.12 & .06 & .25 & -.10 & .01 & .17 & -.14 \\
\hline $\begin{array}{l}\text { Planed } \\
\text { pregnancy }\end{array}$ & -.11 & .05 & -.23 & -.12 & .05 & -.24 & -.02 & .11 & -.14 & -.12 & .01 & -.20 \\
\hline $\begin{array}{l}\text { Depression } \\
\mathrm{T} 1\end{array}$ & - & - & - & $.27^{\star \star}$ & .42 & .10 & .12 & .26 & -.01 & $.14^{*}$ & .24 & .01 \\
\hline $\begin{array}{l}\text { Depression } \\
\text { T } 2\end{array}$ & - & - & - & - & - & - & $.63^{* \star *}$ & .83 & .54 & $.18^{\star}$ & .36 & .02 \\
\hline $\begin{array}{l}\text { Depression } \\
\text { T } 3\end{array}$ & - & - & - & - & - & - & - & - & - & $.56^{\star \star \star}$ & .74 & .41 \\
\hline
\end{tabular}


Table 3

The relationship between the level of anxiety in four evaluation times and other variables studied

\section{Anxiety levels}

\begin{tabular}{|c|c|c|c|c|c|c|c|c|c|c|c|c|}
\hline \multirow[b]{3}{*}{ Age } & \multicolumn{3}{|c|}{ Anxiety T 1} & \multicolumn{3}{|c|}{ Anxiety T2 } & \multicolumn{3}{|c|}{ Anxiety T3 } & \multicolumn{3}{|c|}{ Anxiety T4 } \\
\hline & \multirow{2}{*}{$\begin{array}{l}\text { Beta } \\
.01\end{array}$} & \multicolumn{2}{|c|}{ Cl 95\% } & \multirow{2}{*}{$\begin{array}{l}\text { Beta } \\
-.08\end{array}$} & \multicolumn{2}{|c|}{ Cl 95\% } & \multirow{2}{*}{$\begin{array}{l}\text { Beta } \\
-.07\end{array}$} & \multicolumn{2}{|c|}{ Cl $95 \%$} & \multirow{2}{*}{$\begin{array}{l}\text { Beta } \\
.07\end{array}$} & \multicolumn{2}{|c|}{ Cl 95\% } \\
\hline & & .01 & -.01 & & .01 & -.02 & & .01 & -.02 & & .02 & -.01 \\
\hline $\begin{array}{l}\text { Educational } \\
\text { levels }\end{array}$ & $-.17^{\star}$ & -.02 & -.21 & .12 & .16 & -.02 & .10 & .15 & -.01 & .02 & .11 & -.03 \\
\hline $\begin{array}{l}\text { Wanted } \\
\text { pregnancy }\end{array}$ & -.12 & .04 & -.29 & .14 & .30 & -.03 & .13 & .28 & -.01 & -.10 & .14 & -.10 \\
\hline $\begin{array}{l}\text { Planed } \\
\text { pregnancy }\end{array}$ & $-.20^{\star}$ & -.03 & -.25 & -.13 & .02 & -.20 & .02 & .12 & -.08 & .06 & .02 & -.15 \\
\hline Anxiety T 1 & - & - & - & $.22^{\star \star}$ & .35 & .06 & $.13^{*}$ & .27 & .01 & .17 & .17 & -.07 \\
\hline Anxiety T 2 & - & - & - & - & - & - & $.61^{\star \star \star}$ & .88 & .60 & $.57^{\star}$ & .35 & .03 \\
\hline Anxiety T 3 & - & - & - & - & - & - & - & - & - & $.57^{\star \star \star}$ & .68 & .40 \\
\hline
\end{tabular}

Table 4

Comparison mean of depression and anxiety levels for four evaluations

\begin{tabular}{|c|c|c|c|c|c|c|c|c|c|}
\hline \multirow{3}{*}{$\begin{array}{l}\text { (I) time } \\
\text { Time } 1\end{array}$} & \multirow{3}{*}{$\begin{array}{l}(\mathrm{J}) \text { time } \\
\text { Time } 2\end{array}$} & \multicolumn{4}{|c|}{ Anxiety levels } & \multicolumn{4}{|c|}{ Depression levels } \\
\hline & & \multirow{2}{*}{$\begin{array}{l}(\mathrm{I}-\mathrm{J}) \\
-.33\end{array}$} & \multirow{2}{*}{$\begin{array}{l}\text { sig } \\
<.001\end{array}$} & \multicolumn{2}{|c|}{ Cl $95 \%$} & \multirow{2}{*}{$\begin{array}{l}(\mathrm{I}-\mathrm{J}) \\
-.42\end{array}$} & \multirow{2}{*}{$\begin{array}{l}\text { sig } \\
<.001\end{array}$} & \multicolumn{2}{|l|}{ Cl $95 \%$} \\
\hline & & & & -.22 & -.44 & & & -.33 & -.50 \\
\hline & Time 3 & -.28 & $<.001$ & -.16 & -.39 & -.39 & $<.001$ & -.31 & -.48 \\
\hline & Time 4 & -.23 & $<.001$ & -.12 & -.34 & -.32 & $<.001$ & -.24 & -.40 \\
\hline \multirow[t]{2}{*}{ Time 2} & Time 3 & .06 & ns & .14 & -.02 & .02 & ns & .07 & -.03 \\
\hline & Time 4 & .10 & .02 & .19 & .02 & .09 & .001 & .15 & .04 \\
\hline Time 3 & Time 4 & .05 & ns & .12 & -.03 & .08 & .002 & .13 & .03 \\
\hline
\end{tabular}

The mean anxiety and depression levels increased in the follow-up examinations compared with baseline level $(p<0.001)$. The results of using RMANOVA showed that the effect of time on the level of anxiety and depression in women was significant. However, the effect of women education level and planning status on pregnancy was not significant (Table 5). Using Cochran's test showed that the relative frequency of anxiety (Cochran's $Q$ test = 41.47, DF $=3, p<0.001$ ) and depression (Cochran's $Q$ test $=28.33, \mathrm{DF}=3, \mathrm{p}<0.001$ ) during pregnancy was significant. So that during the second and third evaluation periods, the relative frequency of people reporting levels of anxiety and depression was more than the first visit, but their relative frequency decreased in the third trimester, but did not reach the amount of the first visit. 
Table 5

Trends in depression and anxiety levels at the four assessing times adjusted for confounders

\begin{tabular}{|c|c|c|c|c|c|c|c|c|}
\hline & \multicolumn{2}{|c|}{ Time } & \multicolumn{2}{|c|}{$\begin{array}{l}\text { Educational level of } \\
\text { women }\end{array}$} & \multicolumn{2}{|c|}{$\begin{array}{l}\text { Educational level of } \\
\text { husband }\end{array}$} & \multicolumn{2}{|c|}{$\begin{array}{l}\text { Pregnancy } \\
\text { planning }\end{array}$} \\
\hline & $F^{a}$ & $\mathrm{p}^{\mathrm{a}}$ & $\mathrm{F}^{\mathrm{a}}$ & $p^{a}$ & $F^{a}$ & $\mathrm{p}^{\mathrm{a}}$ & $\mathrm{F}^{\mathrm{a}}$ & $p^{a}$ \\
\hline Anxiety & 8.61 & $<.001$ & .98 & ns & .35 & ns & .97 & ns \\
\hline Depression & 8.55 & $<.001$ & .86 & ns & .80 & ns & .68 & ns \\
\hline
\end{tabular}

\section{Discussion}

The aim of the present study was to evaluate the psychological changes of women with low-risk pregnancies. The results showed that the level of anxiety and depression increases from the beginning of pregnancy to the second trimester of pregnancy and has an inverse relation with the level of education. The relationship between education level and psychological health has already been reported; however, the increase in the level of depression and its relative frequency in the present study is in contrast with the results of other research carried out on the general population and indicated a slowdown in depression during pregnancy [20, 22]. Hu et al also reported that the frequency of depression decreases during the three trimesters of pregnancy [23]. Comparing the prevalence of depression in her study in the first trimester of pregnancy $(14.0 \%)$, with the present study suggests that women with low-risk pregnancy start pregnancy with less depression, but with the advancement of pregnancy, the level of depression increases. This incremental trend observed in the level and relative frequency of depression in Iranian women is consistent with the high prevalence of depression reported in pregnant women in the general population of Iran [24]. Previous studies have been reported that that the prevalence of depression in pregnant women was $22.8 \%$ in the third trimester [25]. With increasing the gestational age, women's need for social support from the family and support for pregnancy delivery systems increases. A study in this field indicates a reverse relationship between the level of depression in women and the belief in the comprehensive support of the pregnancy care systems [24].In a qualitative study, women with a history of postpartum depression stated that lack of social support from the family and care providers caused them discomfort [26]. However, the research findings indicate that the level of social support for Iranian pregnant women is low [27], many of them were not satisfied with the quality of pregnancy care [28]. Although the increase in the level of depression until the second trimester of pregnancy can be explained by the results of these studies, the decrease in depression level in the third trimester of pregnancy was surprising in the present study. Because women's physical constraints due to the increasing age of pregnancy and the common discomfort of this period are factors that can endanger the psychological health of women [29].The findings of this study indicate that the level of depression in women studied was less influenced by the physical conditions of pregnancy. However, although the level of depression in women was dependent on their level of education, the level of depression in them was independent of this factor. So that the changes observed were not related to their educational level. The reverse correlation between education level and depression level has already been reported [30]. In the present study, unlike the Chi study, there was no relationship between the conditions of planning for pregnancy. However, the probability of unwanted pregnancy in women with a lower educational 
level is higher [31]. Therefore, the relationship between unwanted pregnancy and depression may be overshadowed by the level of education.

Another finding of the study showed an increase in the level of anxiety during the first and second trimmers. Also, the results showed that level of anxiety during the first trimester, such as depression level, had a reverse relationship with the level of education of women. In addition, there was a negative relationship between its level and planning for pregnancy. This finding suggests that non-planning for pregnancy, although not affecting the level of depression, is associated with increased anxiety in pregnant women. But increasing the gestational age independent of this factor is associated with an increasing change of anxiety levels. Also, the findings suggest that, unlike depression, the level of anxiety does not decrease in the second and third trimesters.

The observed association between the level of anxiety and planning for pregnancy confirms the results of Gariepy's study, which reported that unplanned pregnancy is associated with an increased risk of anxiety disorder [32]. The relationship between anxiety and maternal education has also been reported in another study [33]. The observed increase in the level of anxiety as well as its prevalence with the progression of pregnancy was also in line with the study of Hu et al., which showed that the anxiety prevalence increased in the second trimester compared to the first trimester. In Zhang's report, the prevalence of pregnancy anxiety increased between the first and second trimester. But in the Zhang study, the prevalence of anxiety was $22.7 \%$ in the first trimester of pregnancy [34]. However, the prevalence of anxiety in this study was $2.8 \%$. This finding suggests that women with uncomplicated pregnancy have better conditions for negative psychological symptoms, but an increase in anxiety is experienced in all women, and this incremental change is not influenced by social status, such as education level.

Other findings showed that the level of depression and anxiety in any of trimester of pregnancy depended on the level of these psychological symptoms in the previous trimester. Other studies have shown that pre-pregnancy depression and anxiety are associated with an increase in the probability of these disorders in pregnancy. The results of this study showed that in people with a history of depression and anxiety disorders in pre-pregnancy, the level of anxiety and depression in the early stages of pregnancy can predict the level of these symptoms in the next stages of pregnancy.

The results of this study indicate that the level of depression and anxiety in women with low complications increases with increasing gestational age, but it should be noted that existing economic fluctuations, which can affect the psychological health of people in society, may have affected the results of the current research and are considered as research constraints.

\section{Conclusion}

This study showed that the change of anxiety prevalence in uncomplicated pregnancies is similar to that of pregnancy is done on the general population, but changes in depression prevalence and level are different in women with uncomplicated pregnancy. These findings suggest that the level of depression during pregnancy is more affected by non-biological conditions than the biological conditions of pregnancy. Also, regarding the increase in the level of anxiety and depression during the second trimester, it is recommended that screening of psychological disorders be performed during the second trimesters in addition to the first trimester.

\section{Abbreviations}


DASS

Depression Anxiety Stress Scales; ANOVA:Analysis of variance; RMANOVA:Repeated Measure Analysis of Variance; SD:Standard deviation; G:group; ns:None significant

\section{Declarations}

Ethics approval and consent to participate

All procedures performed in participants were in accordance with the ethical standards of the Isfahan University of Medical Sciences and informed consent was obtained from all participants.

\section{Consent for publication}

No applicable.

\section{Funding}

This study was funded by Isfahan University of Medical Sciences (Grant number: 496367).

\section{Availability of data and materials}

Data and material are available on request from the corresponding author.

\section{Competing interests}

The authors declare that they have no conflict of interest.

\section{Authors' contributions}

AK: Project development, Data collection supervising, acquisition of analysis, interpretation of data and editing the manuscript AD: Project development, Data Collection, Manuscript writing. Also, all authors have read and approved the manuscript.

\section{References}

1. Schaffir J. Consequences of Antepartum Depression. Clin Obstet Gynecol. 2018;61(3):533-43.

2. Ogunyemi D, Jovanovski A, Liu J, Friedman P, Sugiyama N, Creps J, et al. The Contribution of Untreated and Treated Anxiety and Depression to Prenatal, Intrapartum, and Neonatal Outcomes. AJP Rep. 2018;8(3):E146-E57.

3. Reck C, Zimmer K, Dubber S, Zipser B, Schlehe B, Gawlik S. The influence of general anxiety and childbirthspecific anxiety on birth outcome. Arch Womens Ment Health. 2013;16(5):363-9.

4. Stewart RC, Ashorn P, Umar E, Dewey KG, Ashorn U, Creed F, et al. Associations between antenatal depression and neonatal outcomes in Malawi. 2018:e12709.

5. Lima SAM, El Dib RP, Rodrigues MRK, Ferraz GAR, Molina AC, Neto CAP, et al. Is the risk of low birth weight or preterm labor greater when maternal stress is experienced during pregnancy? A systematic review and meta-analysis of cohort studies. PLoS One. 2018;13(7):15. 
6. Adamson B, Letourneau N, Lebel C. Prenatal maternal anxiety and children's brain structure and function: A systematic review of neuroimaging studies. J Affect Disord. 2018;241:117-26.

7. Rodriguez VJ, Mandell LN, Babayigit S, Manohar RR, Weiss SM, Jones DL. Correlates of Suicidal Ideation During Pregnancy and Postpartum Among Women Living with HIV in Rural South Africa. AIDS Behav. 2018;22(10):3188-97.

8. Gobel A, Stuhrmann LY, Harder S, Schulte-Markwort M, Mudra S. The association between maternal-fetal bonding and prenatal anxiety: An explanatory analysis and systematic review. J Affect Disord. 2018;239:313-27.

9. Sutter-Dallay AL, Giaconne-Marcesche V, Glatigny-Dallay E, Verdoux H. Women with anxiety disorders during pregnancy are at increased risk of intense postnatal depressive symptoms: a prospective survey of the MATQUID cohort. Eur Psychiat. 2004;19(8):459-63.

10. Erbil N. Sexual function of pregnant women in the third trimester. Alex J Med. 2018;54(2):139-42.

11. Shojaa M, Jouybari LM, Sanagoo A. Common myths among a group of Iranian women concerning sexual relationships during pregnancy. Arch Med Sci. 2009;5(2):229-32.

12. Lagadec N, Steinecker M, Kapassi A, Magnier AM, Chastang J, Robert S, et al. Factors influencing the quality of life of pregnant women: a systematic review. BMC Pregnancy Childbirth. 2018;18:14.

13. van de Loo KFE, Vlenterie R, Nikkels SJ, Merkus P, Roukema J, Verhaak CM, et al. Depression and anxiety during pregnancy: The influence of maternal characteristics. Birth-Issue Perinat Care. 2018;45(4):478-89.

14. Dagklis T, Tsakiridis I, Chouliara F, Mamopoulos A, Rousso D, Athanasiadis A, et al. Antenatal depression among women hospitalized due to threatened preterm labor in a high-risk pregnancy unit in Greece. J Matern-Fetal Neonatal Med. 2018;31(7):919-25.

15. Furtado M, Chow CHT, Owais S, Frey BN, Van Lieshout RJ. Risk factors of new onset anxiety and anxiety exacerbation in the perinatal period: A systematic review and meta-analysis. J Affect Disord. 2018;238:626-35.

16. Polachek IS, Dulitzky M, Margolis-Dorfman L, Simchen MJ. A simple model for prediction postpartum PTSD in high-risk pregnancies. Arch Womens Ment Health. 2016;19(3):483-90.

17. Alipour Z, Kheirabadi GR, Kazemi A, Fooladi M. The most important risk factors affecting mental health during pregnancy: a systematic review. Eastern Mediterranean health journal = La revue de sante de la Mediterranee orientale = al-Majallah al-sihhiyah li-sharq al-mutawassit. 2018;24(6):549-559.

18. Topalahmetoglu Y, Altay MM, Akdag Cirik D, Tohma YA, Colak E, Coskun B, et al. Depression and anxiety disorder in hyperemesis gravidarum: A prospective case-control study. Turkish journal of obstetrics gynecology. 2017;14(4):214-9.

19. Darwin Z, McGowan L, Edozien LC. Antenatal mental health referrals: Review of local clinical practice and pregnant women's experiences in England. Midwifery. 2015;31(3):E17-22.

20. Carter EA, Bond MJ, Wickham RE, Barrera AZ. Perinatal depression among a global sample of Spanishspeaking women: A sequential-process latent growth-curve analysis. J Affect Disord. 2019;243:145-52.

21. Sahebi A, Asghari MJ, Salari R. [Validation of depression anxiety stress scale (DASS-21) for Iranian population]. J Iran Psychol. 2005;1(4):299-312.

22. Ahmed A, Feng C, Bowen A, Muhajarine N. Latent trajectory groups of perinatal depressive and anxiety symptoms from pregnancy to early postpartum and their antenatal risk factors. Arch Women Ment Health. 
2018;21(6):689-98.

23. Hu HQ, Zhang J, Zhao W, Tian T, Huang AQ, Wang LL. [The occurrence and determinants of anxiety and depression symptoms in women of six counties/ districts in China during pregnancy]. Zhonghua yu fang yi xue za zhi [Chinese journal of preventive medicine]. 2017;51(1):47-52.

24. Moshki M, Cheravi K. Relationships among depression during pregnancy, social support and health locus of control among Iranian pregnant women. Int J Soc Psychiatry. 2016;62(2):148-55.

25. Kheirabadi GR, Maracy MR. Perinatal depression in a cohort study on Iranian women. Journal of research in medical sciences: the official journal of Isfahan University of Medical Sciences. 2010;15(1):41-9.

26. Kazemi A, Ghaedrahmati M, Kheirabadi GR, Ebrahimi A, Bahrami M. The Experiences of Pregnancy and Childbirth in Women with Postpartum Depression: A Qualitative Study. Iran J Psychiatry Behav Sci. 2018;12(4):e66998.

27. Bani S, Hasanpour S, Mohammadalizadeh S, Mirghafourvand M, Salimi R, Iranzad I. Social support during pregnancy and its relationship with anthropometric indices at birth and postnatal depression in Iranian women. World Fam Med. 2018;16(4):71-5.

28. Faisal I, Matinnia N, Hejar AR, Khodakarami Z. Why do primigravidae request caesarean section in a normal pregnancy? A qualitative study in Iran. Midwifery. 2014;30(2):227-33.

29. Malmqvist S, Kjaermann I, Andersen K, Okland I, Larsen JP, Bronnick K. The association between pelvic girdle pain and sick leave during pregnancy; a retrospective study of a Norwegian population. BMC Pregnancy Childbirth. 2015;15:8.

30. Chi X, Zhang P, Wu H, Wang J. Screening for Postpartum Depression and Associated Factors Among Women in China: A Cross-Sectional Study. Frontiers in psychology. 2016;7:1668.

31. Ali SA, Tikmani SS, Qidwai W. Prevalence and determinants of Unintended Pregnancy: Systematic Review. World Fam Med. 2016;14(6):37-46.

32. Gariepy AM, Lundsberg LS, Miller D, Stanwood NL, Yonkers KA. Are pregnancy planning and pregnancy timing associated with maternal psychiatric illness, psychological distress and support during pregnancy? J Affect Disord. 2016;205:87-94.

33. Kang YT, Yao Y, Dou J, Guo X, Li SY, Zhao CN, et al. Prevalence and Risk Factors of Maternal Anxiety in Late Pregnancy in China. Int J Environ Res Public Health. 2016;13(5):e468.

34. Zhang YD, Muyiduli X, Wang SJ, Jiang W, Wu JH, Li MC, et al. Prevalence and relevant factors of anxiety and depression among pregnant women in a cohort study from south-east China. J Reprod Infant Psychol. 2018;36(5):519-29. 